\title{
Perceptions and Uses of Technology among Adolescent Boys and Girls
}

\author{
Alice A. Christie \\ Arizona State University West, PO Box 37100 MC 3151, Phoenix, AZ 85069-7100, USA \\ alice.christie@asu.edu
}

Keywords: barriers, collaborative learning, culture, learner-centered learning, research

\begin{abstract}
In this study, I used interpretive methods in an open-ended computer environment to study and explain gender diversity in middle school computer classrooms. Through observations and a series of focus groups, I found that adolescent boys and girls view and use computers differently. Each gender seems to accept this as a natural part of their culture, and, in general, are accepting of each other's visions and uses. Turkle and Papert called for a new social construction of the computer to contribute to our understanding of the ways males and females think about and use computers. This paper answers that call. It breaks ground for future studies to create, and simultaneously study, computer cultures which honour female and male ways of knowing and which allow the research community to begin to break down gender stereotypes and the idea of one privileged - usually male - way of thinking about computers.
\end{abstract}

\section{INTRODUCTION}

Both the popular and academic press point to a gender gap in computer use, computer competency, computer attitudes, and in the ways men and women view the computer. However, some question this commonly held belief. Turkle and Papert (1990) call for the development of a new computer culture which "would require a new social construction of the computer" (p. 133), which is, in turn, more inclusive than the existing male-dominated culture. They cite the work of feminist scholar, Gilligan (1982), who 
questions the "idea of one privileged, mature way of thinking" (p. 123) as parallel to their view of "the computer as a projective screen for different approaches to knowledge" (p. 134).

Morse and Daiute (1992) identified a need for "more research on computing activities which are not related to mathematics or programming activities and which look at what women and girls do like about computers" (p. i). They believe that most research to date is quantitative and has "shortchanged girls and women in documenting the computer gender gap" (p. 1). They state that Likert scale questionnaires are an especially inaccurate "way to measure female responses to computing" (p. 5) They state the need for more research using interpretive methods in open-ended computer environments so that we might better study and explain gender diversity in our computer classrooms.

In this study I seek to answer this call for a new kind of research. I assume, as does Gilligan (1982), that the way people talk and write about their lives is significant, that the language they use and the connections they make reveal the world as they see it.

In this study, I used interpretive methods in an open-ended computer environment so that I might better study and explain gender diversity in middle school computer classrooms. I hoped to gain insight into how girls and boys conceptualised and used computers - not just if there were differences in how boys and girls used and felt toward computers. By focusing particularly though not exclusively on girls, who historically are either left out or underrepresented in studies of technology, I hope to shed light on how girls view their experiences with technology. Gilligan (1982) recounts how she used "the group left out in the construction of theory to call attention to what is missing in its account" (p. 4). I hope this study of what is often missing will allow us to abandon our previous understandings of how humanity views technology (which were based on a predominantly male view) and adopt a more encompassing view of all people and technology.

\section{THEORETICAL STANCE}

Theoretically, I view both gender and the computer as social and cultural constructions. Gender is assumed to be constructed within a culture and not genetically inherent in an individual (i.e., gender is not something we are, but something we do) (West and Zimmerman 1987). Doing gender is unavoidable; one can never 'not do' gender. Technologies do not exist in a vacuum - with no history and no social implications or connections. Technologies exist only in social contexts, and as such, exist in a gendered 
world. And as Benston (1985) stated so succinctly, technology is gendered and its gender is male. I also view the classroom as a community of learners where power is shared and where participatory, democratic processes help learners develop independence. This classroom is collaborative, co-operative and interactive. It is an active classroom where risk-taking is encouraged, where intellectual excitement abounds and where power is viewed as energy, capacity, and potential rather than domination.

\section{LITERATURE REVIEW}

A review of several hundred empirical studies on gender and computers conducted between 1984 and the present paints an overall picture of male dominance. Males used computers more than females, especially for programming and game playing. This tendency begins in elementary school where boys tended to dominate computer use and often 'crowded girls out'. In addition, three times as many boys as girls participated in summer computer camps, and parents were more likely to purchase computers, computer software and peripherals for boys than for girls. By high school, the gender gap in computer use was even more pronounced. Boys were more likely to own a computer, understand the electronic operations of computers and be part of extracurricular computer classes. The trend continued at the college level where, in an introductory computer course, more than half the males used the computer lab after hours while almost none of the females took advantage of this opportunity. At all levels, boys were more likely to be chosen to assist the teacher with technology than were girls (Sanders 1990). Christie (1995) observed that girls generally enjoyed computing less than boys because most available software appeals to boys rather than to girls; the software uses gaming formats which are competitive and often violent and which pit two players against each other or one player against the computer. And finally, male teachers used computers more than female teachers at the elementary, secondary, and university levels (Hattie and Fitzgerald 1987). Therefore students lacked female role models in this domain.

Gender stereotyping attitudes were more decisive. When surveying 1,600 Kindergarten through grade 12 students, Wilder, Mackie and Cooper (1985) found that both boys and girls considered computers as more appropriate for males than females. When asked to draw a computer user, both boys and girls were more likely to draw boys in this role (Martin, Heller and Mahmoud 1992). Gender stereotypes, such as these, were reinforced by parents, peers, and the educational system (Walkerdine 1990). 


\section{DESCRIPTION OF THE STUDY}

The focus in my study is not to further investigate the perceived gender gap in terms of technology, but rather to address the meanings that adolescents assign to computers as they interact with them more and more in today's world. West and Fenstermaker (1993) believe that gender is "a mechanism whereby situated social action contributes to the reproduction of social structure in which people $d o$ gender; and men and women do it differently" (p.158). In a similar vein, objects, such as computers, take on meanings constructed by individuals as they interact with these objects. People negotiate and renegotiate meaning as they personally interact with objects, thereby constructing a social order as well as a personal meaning. Within this perspective, computers are social constructions that vary from person to person. This research delves into these personal meanings.

In my role of teacher/researcher, I co-taught a technology-rich social science unit to 250 middle school students. My team-mate and I worked with each group of 25-30 students for approximately eight to ten hours in four separate sessions. Data sources included:

- Open-ended student surveys about their uses of and attitudes toward technology

- Open-ended parent surveys about their uses of and attitudes toward technology

- Field notes and observational data

- Documents data

- Structured focus groups data.

As this study is still ongoing, this paper includes only data from nineteen structured focus groups with 94 students. Each focus group included four to six middle school students. I conducted focus groups at eight schools with the configurations listed below:

\begin{tabular}{lll}
\hline School & Number of Students & $\begin{array}{l}\text { Gender } \\
\text { Configuration }\end{array}$ \\
\hline School 1 & 4 students & All Boys \\
Three Focus Groups & 5 students & 2 Boys and 3 Girls \\
& 5 students & All Girls \\
School 2 & 5 students & 2 Boys and 3 Girls \\
Two Focus Groups & 6 students & All Girls \\
School 3 & 6 students & All Boys \\
Two Focus Groups & 5 students & All Girls \\
School 4 & 6 students & All Girls \\
Two Focus Groups & 5 students & All Boys \\
School 5 & 4 students & 1 Boy and 3 Girls \\
\hline
\end{tabular}




\begin{tabular}{lll}
\hline School & Number of Students & $\begin{array}{l}\text { Gender } \\
\text { Configuration }\end{array}$ \\
\hline Two Focus Groups & 4 students & All Girls \\
School 6 & 4 students & 2 Boys and 2 Girls \\
Three Focus Groups & 5 students & All Girls \\
& 5 students & 1 Boy and 4 Girls \\
School 7 & 4 students & All Boys \\
Three Focus Groups & 5 students & All Girls \\
& 5 students & All Girls \\
School 8 & 5 students & All Girls \\
Two Focus Groups & 6 students & 3 Boys and 3 Girls \\
\hline
\end{tabular}

\subsection{Girls' definitions of computer}

The following lists reflects the major definitions seventh and eighth grade girls gave to the construct computer:

- I don't know how to define a computer technically

- Something to keep you connected to your friends

- It helps you communicate with others

- A machine that does things that you tell it to do

- A lot of stuff combined into one thing to make life easier

- A gateway to information

- It can substitute for a book because it contains so much information

- It organises and stores your thoughts

- It's a resource tool for learning things

- It can communicate, it can do problems in math and it can write

- It improves your everyday life

- A tool that makes your work look neater and more professional

- A tool that helps you work quicker

- It's whatever you want it to be.

\subsection{Girls' uses of computers}

Girls used computers in a number of ways. The following list summarises uses identified by seventh and eighth grade girls:

- Word processing for homework and research

- Word processing for writing process to easily do lots of drafts

- PowerPoint presentations for classes

- Email to talk to friends both locally and at a distance

- Chat rooms to keep in touch with friends and make new friends

- Instant messaging to talk to classmates 
- Email to talk to guys and flirt with guys

- Games to play if I'm really, really bored, like PacMan or Solitaire

- Definitely NOT for games

- The Internet to shop or 'window shop'.

\subsection{Boys' definitions of computer}

The following lists reflects the major definitions seventh and eighth grade boys gave to the construct computer:

- A machine with a CPU and a motherboard and circuits

- A high tech calculator, a giant calculator

- A machine that does what you program it to do

- A machine that thinks for you

- A machine that processes information and stores it

- A toy for people to have for entertainment

- A machine that does things faster than a human can

- A machine that allows you to look up stuff

- It let's you do things quicker and easier.

\subsection{Boys' uses of computers}

Boys used computers in a number of ways. The following list summarises uses identified by seventh and eighth grade boys:

- Mainly for fun, maybe some homework now and then

- To play games (Solitaire, casino games, sporting games, logic games, simulations where you kill people, war games)

- Entertainment 24 hours a day

- The Internet for information to do homework

- The Internet for Nintendo codes

- Run an FTP from my computer that's up 24 hours a day.

\section{INTERPRETATIONS}

All of the adolescent boys and girls in this study were competent, confident and frequent users of computers, computer software, and the Internet. Despite their equivalent competence, confidence and frequency of use, girls and boys view and use computers differently.

In terms of definitions, girls saw the computer as much more multidimensional then did boys. The phrase it's whatever you want it to be best captures this understanding. Girls defined computers as multi-use tools that 
facilitate connecting with friends, doing homework and research, gathering information, solving math problems, organising ideas and information, producing more professional products, and accomplishing a multitude of tasks in a quicker, easier way. Boys, on the other hand, had a more narrow view of computers. Boys identified computers as machines, toys, or high tech calculators that let you do things quicker and easier. It is interesting that no girls used the terms machine or toy in defining the computer. Rather, they focused on what the computer allowed them to accomplish. The major foci for girls, in order of importance, were computer as communication tool, computer as productivity tool, and computer as multi-purpose tool. The major foci for boys, in order of importance, were a machine for entertainment and gaming, a thinking machine, and an information machine.

In terms of general use, girls used computers to connect with others, and boys used computers to compete with others. Girls' most predominant uses centred around communication: emailing friends and family, chatting with friends, making new friends, using instant messaging to communicate daily with classmates, and connecting and flirting with guys. Boys' most predominant uses centred on competitive, often violent, gaming activities such as war games and killing-people simulations, and sporting games. In terms of school-related use, girls focused on the numerous ways they used computers, including word processing, creating multimedia presentations, writing multiple drafts of papers, and producing neat, professional looking work. Boys, however, mentioned that they used computers for homework and schoolwork only now and then, and the only tool they mentioned was the Internet.

In terms of Internet use, each gender identified several uses not mentioned by the other gender. Girls said they used the Internet to shop or browse for fashion ideas. They also focused on using the Internet to flirt with guys or see pictures of 'handsome hunks.' Boys mentioned using the Internet to look up codes for various games that would allow them to move to the next level of the game. And several boys mentioned their sophisticated use of computers to create FTP sites for other gamers to find codes and secrets for popular software and Internet games. Interestingly, the only critical note of the focus group sessions was several groups of girls saying that they played computer games not at all or only when they were very, very bored. They then elaborated that they thought computers games were bad influences on their male classmates because gaming made the boys into antisocial couch potatoes who didn't know how to communicate with their female classmates.

An interesting and unexpected trend that I discovered when analysing data was that girls used more exact language to describe computer use than did boys. For example, boys said the used computers for homework; girls 
specified that that used word processing, PowerPoint and the Internet to do homework. Boys called the computer a machine that allows you to look up stuff, while girls said it was a resource tool for learning things. Boys were less specific about their uses than girls. For example, boys never mentioned how they did homework, while girls mentioned how they used word processors to do multiple drafts and how using the computer made their work look neater and more professional. And even though both boys and girls mentioned the convenience of computers, they chose different language to express this idea. Boys used the generic it when they said it let's you do things quicker and easier; girls identified the computer as a tool when they said it's a tool that helps you work quicker.

\section{CONCLUSION}

Adolescent boys and girls view and use computers differently. Each gender seems to accept this as a natural part of their culture, and, in general, are accepting of each other's visions and uses. Turkle and Papert (1990) called for a new social construction of the computer to contribute to our understanding of the ways males and females think about and use computers. This paper answers that call. It breaks ground for future studies to create, and simultaneously study, computer cultures which honour female and male ways of knowing and which allow the research community to begin to break down gender stereotypes and the idea of one privileged (usually male) way of thinking about computers.

\section{REFERENCES}

Benston, M. L. (1985) The myth of computer literacy. Canadian Women's Studies, 5, pp. 2022.

Christie, A. A. (1995) No chips on their shoulders: Girls, boys and telecommunications. (Doctoral dissertation, Arizona State University, 1995). Dissertation Abstracts International, 56 (11A), 96-08340.

Gilligan, C. (1982) In a different voice: Psychological theory and women's development. Harvard University Press, Cambridge.

Hattie, J. and Fitzgerald, D. (1987) Sex differences in attitudes, achievement and use of computers. Australian Journal of Education, 31, pp. 3-26.

Martin, C. D., Heller, R. S. and Mahmoud, E. (1992) American and Soviet children's attitudes toward computers. Journal of Educational Computing Research, 8, pp. 155-186.

Morse, F. K. and Daiute, C. (1992, April) I LIKE computers vs. I LIKERT computers: Rethinking methods for assessing the gender gap in computing (Research Rep. No. ED 349 939). American Educational Research Association Conference, San Francisco. 
Sanders, J. (1990, July) Computer equity for girls: What keeps it from happening. In Fifth World Conference on Computers in Education in Sydney, Australia, Amsterdam, Elsevier Science Publishing, pp. 181-185.

Turkle, S. and Papert, S. (1990) Epistemological pluralism: Styles and voices within the computer culture. SIGNS Magazine, 16(1), pp. 128-157.

Walkerdine, V. (1990) Schoolgirl fictions. Verso, London.

West, C. and Fenstermaker, S. (eds.) (1993) Power, inequity and the accomplishment of gender: An ethnomethodological view. Aldine, New York.

West, C. and Zimmerman, D. H. (1987) Doing gender. Gender \& Society, 1(2), pp. 125-151.

Wilder, G., Mackie, D. and Cooper, J. (1985) Gender and computers: Two surveys of computer-related attitudes. Sex Roles, 13, pp. 215-228.

\section{BIOGRAPHY}

Dr. Alice Christie has been a teacher since 1967, serving in elementary and secondary schools and most recently at the university level. She received a B.A in English from Denison University, a M.Ed. in Reading Education from Boston University and a Ph.D. in Elementary Education with concentrations in Language and Literacy and Educational Technology from Arizona State University. She joined the ASU West Faculty in 1995 and currently serves as Associate Professor of Technology and Education.

Her research interests include gender and technology and literacy and technology. Her research focuses on ways in which females can become competent, confident and active users of technology as well as on ways technology can enhance literacy in elementary school children. www.west.asu.edu/achristie is her educational web-site. 